\title{
OPEN
}

\section{Introduction: Address as Social Action Across Cultures and Contexts}

\author{
Catrin Norrby and Camilla Wide
}

\begin{abstract}
The introduction provides a brief overview of address research, particularly focusing on address practices in Europe. It also serves to contextualize the six chapters of the volume, all of which present up-to-date empirical research of address and social relations in a variety of contexts and languages including Dutch, French, Finnish, German, Italian and Swedish.
\end{abstract}

Keywords: European languages; pragmatics; address; social relationships; interpersonal relationships

Norrby, Catrin, and Camilla Wide, eds. Address Practice As Social Action: European Perspectives. Basingstoke: Palgrave Macmillan, 2015. DOI: 10.1057/9781137529923.0006. 


\section{Address practices in Europe}

The way we address one another is crucial for establishing and maintaining social relationships. In our daily encounters, we regulate the level of social distance between us and our fellow interlocutors through our choice of address terms such as pronouns, first names, last names and titles. Our choice is also guided by the level of formality of the situation and the particular context - we use different address terms in a work interview and when having dinner with friends. English only has one address pronoun (you), but it nevertheless has many words and expressions for marking interpersonal relationships. For example, one and the same person can be addressed by different interlocutors such as Sue, Susan or Ms Smith, revealing different levels of familiarity and affinity with the addressee. Similarly, getting somebody's attention with Hey you or with Excuse me, Madam would most likely be interpreted very differently in terms of politeness and formality.

Many other languages make a distinction between a familiar/informal address pronoun, often referred to as ' $\mathrm{T}$ ' from Latin $t u$, and a 'polite' or more formal counterpart, labelled ' $\mathrm{V}$ ' from Latin vos (Brown and Gilman, 1960, p. 254). However, the selection of one particular address pronoun over another - what is considered the 'right' form of address in a particular situation - varies over time, across speech communities, social networks, and even according to individual preference (Clyne, Norrby and Warren, 2009). In other words, address in a given language is not a static system but is better understood as a dynamic resource for negotiating and establishing social relationships in interaction that resonates with the overall sociocultural values of a particular speech community, social network or community of practice.

In continental Europe, $\mathrm{V}$ address is generally used as the 'default' address (see Clyne, Norrby and Warren, 2009) to strangers and between interlocutors who are not family or close friends. It marks more formal or distant relationships and is usually interpreted as a 'polite' or neutral form of address, while $\mathrm{T}$ address is reserved for more long-term and closer relationships. In Scandinavia, $\mathrm{V}$ address was used in a somewhat similar way as in continental Europe until around 50 years ago. Since then the use of $\mathrm{V}$ address has drastically declined. This has been partly as an outcome of the egalitarian and democratic ideals that gained ground in Scandinavia from the 1960s onwards (Paulston, 1976), and also because $\mathrm{V}$ address was not unequivocally seen as a polite form in 
all situations. For example, in Sweden, $\mathrm{V}$ address could be used to mark social inferiority (see Chapters 3 and 4 in this volume). As pointed out by Fredsted (2005, p. 159), '[i]t is not good "tone" in the Scandinavian welfare states to show off, demonstrate wealth or superiority'.

$\mathrm{T}$ address has now become the default form in almost all situations in Scandinavia, even though there is some variation across countries. In Denmark and Finland in particular, $\mathrm{V}$ address has been maintained to some extent, especially in situations such as service encounters. This has resulted in an intricate system where the choice between $\mathrm{T}$ and $\mathrm{V}$ is governed by a number of factors that may vary between different age groups, different regions, different social groups but also between individual speakers (see, for example, Trap-Jensen, 1995; Hickey and Stewart, 2005, chapters 10-12; Clyne, Norrby and Warren, 2009). In Finland, where Finnish and Swedish are spoken, both $\mathrm{T}$ and $\mathrm{V}$ address can be received as either neutral, polite or impolite in service encounters and other similar situations. Not surprisingly, a quite common strategy in Finland (especially in Finnish but also in Finland Swedish) is to avoid direct address and use various types of impersonal constructions instead (see Yli-Vakkuri, 2005). This and other phenomena connected to the ambivalent status of $\mathrm{V}$ address as a polite form illustrate the differences between address patterns in Scandinavia and continental Europe. These distinctions need be taken into consideration when comparisons are made between these two parts of Europe.

\section{Research on address}

The beginnings of address research are often associated with the publication of Brown and Gilman's 1960 article 'The pronouns of power and solidarity' and their distinction between 'polite' $\mathrm{V}$ address pronouns and 'familiar' T pronouns (Brown and Gilman, 1960). They linked V and $\mathrm{T}$ pronouns to the dichotomy of 'power' and 'solidarity', thought to be universal, where reciprocal use of $\mathrm{T}$ or $\mathrm{V}$ was interpreted as what they called a 'solidarity semantic', and non-reciprocal use of $\mathrm{V}$ by one interlocutor and $\mathrm{T}$ by the other was represented as a 'power semantic'. Their model has stimulated much research, but it has also been criticized for making too far-reaching, even universal, claims based on limited empirical data drawn exclusively from major European languages with a binary T/V distinction (Braun, 1988; Mühlhäusler and Harré, 1990). 
As shown by Braun (1988), for example, many languages boast a range of address pronouns and do not fit into a dichotomy such as the one proposed by Brown and Gilman. A significant aspect of Brown and Gilman's work is their prediction that reciprocal use of informal $\mathrm{T}$ (the solidarity dimension) would eventually replace non-reciprocal T/V (the power dimension). Broadly speaking, such a generalization rings true with the development in many Western nations over the past 50-60 years, where movements away from hierarchical towards more egalitarian and democratic societies have developed hand in hand with a more informal, even intimate, tone in public discourse. While this general informalization of ways of speaking and acting extends also to address conventions in the languages and speech communities investigated in this volume, the research reported in the six chapters also demonstrates that the situation is far more complex and contradictory.

Brown and Gilman's study precedes the advent of sociolinguistics with its focus on social categories such as class, age and gender. Sociolinguistics brought an interest in the variation in address usage and argued that different social groups within the same speech community might adhere to different rules of use (Ervin-Tripp, 1986; Paulston, 1976). In particular, this would be the case in times of transition. Take, for example, the rapid shift towards general use of $\mathrm{T}$ address in Swedish society in the late 1960 s and early 1970 s where some groups reserved $T$ for friends and family, while others extended T much more broadly (Paulston, 1976). While ongoing change in address practices might eventually lead to a new shared and 'stable' usage - as predicted by Brown and Gilman there is also evidence of cyclical development. In their study on styles of address in French, German and Swedish, Clyne, Norrby and Warren (2009) showed that the widespread use of $\mathrm{T}$ address in the 1960s as part of the student movement in Europe has since diminished in French and German. It is now found in limited use among networks of 'like-minded' people - belonging to the same sports club, or being part of the same street demonstration, for example, can trigger $\mathrm{T}$ address - and in the university domain (pp. 160-1).

Sociolinguistics has seen a development from large-scale studies of variation in the ways people use language in their speech communities towards smaller-scale investigations focusing on interactional and contextual details. This shift in focus is also evident in address research where more recent studies have explored the address choices participants make in a variety of contexts and with different 
interlocutors. These studies have used a range of methods for observing and recording the address terms people use, including canvassing their reported use and their attitudes towards address through questionnaires, focus groups, semi-structured interviews and participant observation (see, for example, Clyne, Norrby and Warren, 2009), as well as the analysis of actual address use in interaction (see, for example, Gardner-Chloros, 2007; Norrby, Wide, Lindström and Nilsson, 2015). Similarly, the chapters of this volume make use of a variety of methods, with a clear leaning towards analysing address practice in actual interactions.

Given that address is a powerful instrument for marking social relationships, it involves issues of politeness (for example, Leech, 1983; Brown and Levinson, 1987; Watts, 2003), perceptions of common ground (Clark, 1996; Svennevig, 1999) and social distance (Brown and Levinson, 1987; see also Svennevig, 1999, for social distance as a multidimensional concept involving the dimensions of solidarity, familiarity and affect). In their model, Brown and Gilman interpreted social distance as the non-hierarchical 'solidarity' dimension, leading to reciprocal address use - interlocutors using the same address terms. Difference in status and power relations would lead to non-reciprocal use, with a more 'powerful' speaker using $\mathrm{T}$ to address somebody further down the rungs of hierarchy but expecting a 'respectful' V back.

While such power semantics were more commonplace in the past, other parameters such as style and identity have surfaced as important for the choice of address. Following Agha's work on person deixis (2007, pp. 278-9), we could say that conventional social meanings associated with a certain address form - for example, that German Sie or French vous (V pronouns) are 'polite' - are 'taken up, challenged and renegotiated by individuals in their situated identity work' (Clyne, Norrby and Warren, 2009, p. 30). While use of Sie or vous would be the 'default', unmarked form of address to an adult stranger in German and French, at first encounter two strangers could use $\mathrm{T}$ with each other on the basis of perceived commonalities and a wish to express sameness and affinity. Clyne, Norrby and Warren (pp. 69-78) provide numerous examples of how individuals consider which address form to use by 'reading' the situation and the interlocutor, based on overt style and identity markers including clothing, accessories, hairstyle and general appearance as well as other more indirect ones, such as political orientation, religion, or taste in music to name a few. 


\section{The chapters in this volume}

The chapters in this collection reflect the authors' interest in the role of language as a form of action through which identities, social relations and group memberships are constructed and negotiated. They highlight the importance of investigating the everyday encounters and interactions that make up the social fabric of our lives. While some of the communities presented are characterized by general consensus and relatively stable address practices, others display heterogeneity and are sites of negotiation and even opposition. By comparing local, national and transnational address practices, this volume uncovers both commonalities and differences in the way social meaning is expressed and shaped through address.

The volume is distinctive in three main ways. First, it presents a selection of the latest research on address practices in a number of European languages. The overall aim is to increase our understanding of how address practices vary across languages, speech communities, situations and time, and the implications such variation has for cross-cultural communication - between speakers of different languages as well as speakers of different varieties of the same language.

Second, the majority of chapters focus on actual address usage in authentic written or spoken interactions. This is in contrast to most address research to date, which has focused on reported use and attitudes to address (for an overview see Norrby and Warren, 2012). In this sense, the volume fills a research gap by providing a long overdue analysis of actual address in a variety of activities and contexts. Together, the chapters contribute to a better understanding of address practice in a variety of European languages, ranging from widely spoken languages such as French, German and Italian to less widely used languages such as Dutch, Finnish and Swedish.

Third, the volume is innovative in that it explores a wide range of real-life and mediated interactional contexts: (a) audio and visual media - radio interviews, film commercials and feature films; (b) service encounters - in coffee houses and at theatre box offices; (c) computermediated communication in internet forums; and (d) academic interactions in a university setting. Variation in address choice is a central theme in all the chapters - the languages under investigation all have pronominal and nominal address terms, but the way these resources are put to work vary significantly across languages, speech communities 
and settings. Some chapters highlight national variation in the address patterns of pluricentric languages - languages that have more than one national centre or official status in more than one country (Clyne, 1992). The focus is on national varieties of Dutch (Chapter 1), German (Chapter 2) and Swedish (Chapter 4). Others contrast address preferences in different languages (Chapter 5), in different locations and situations (Chapter 6), or document changes in address over time within the same speech community (Chapter 3 ).

In Chapter 1, Roel Vismans investigates address practices in conversations with Dutch and Flemish speakers. There are subtle differences between the northern - Netherlands - and southern - Flemish (Belgium) - parts of the Dutch-speaking area, both in terms of the actual address pronoun system and how the more formal and informal forms of address are used. To explore how these differences are realized in actual usage, the chapter analyses in-depth radio interviews between Dutch journalists and Flemish academics. In a qualitative analysis it tracks the development of the relationship between the speakers and their use of address forms, as well as other markers of (in)formality. It takes into account other possible factors affecting the interaction (age, gender, residence in the other country) and pays special attention to speakers' commentary on the variation between informal pronominal address $(\mathrm{T})$ and formal address $(\mathrm{V})$. The chapter shows that the rules of engagement for address in the standard language (that is, when to use $\mathrm{T}$ and when to use $\mathrm{V}$ ) are not the same in the Netherlands and Flanders. Dutch speakers from Flanders are more likely to use $\mathrm{V}$ forms in situations where speakers from the Netherlands use $\mathrm{T}$ forms. This is at least in part due to the fact that southern colloquial Dutch has regional forms of address that do not entirely match those of standard Dutch. The study thus adds to the growing evidence that Belgian Dutch continues to maintain its distinctiveness from the Netherlands norm.

In Chapter 2, Heinz L. Kretzenbacher and Doris Schüpbach present a case study on address practices based on a corpus of readers' forums in German, Austrian and Swiss newspapers. Address in computer-mediated communication (CMC) is a relatively new field both in address research and in CMC research. This is partly due to the fact that the majority of CMC research has been carried out on (Standard) English, where address is not such an obvious phenomenon, given the language's single address pronoun 'you'. In contrast, German makes a distinction (and therefore requires a choice) between the formal V address pronoun Sie 
and informal $\mathrm{T}$ pronoun $d u$. In offline interactions, $\mathrm{V}$ is the unmarked form of address between strangers. However, it has often been assumed that the German-speaking Internet would almost exclusively use $\mathrm{T}$ address. This is linked to a view of the Internet as a setting where users have a sense of belonging to a community based on affinity and common interests, naturally leading to T. However, as Kretzenbacher and Schüpbach show, this is not the case. The results of their study show that the majority of Internet posts actually do not use any explicit address at all, and in those cases where direct address appears, V is by far the most common form. The authors compare the three national varieties of German in Germany, Austria and Switzerland. They find that V is the only direct form of address in Swiss forums and the most prevalent form in German forums, while Austrian forums display a more mixed picture. The authors conclude that the variation can be linked to factors other than national preference, including whether participants appear under a real name or a nickname, the individual preferences of contributors, as well as the type of forum.

In Chapter 3, Maria Fremer turns our attention to changes in address practices over time. The chapter documents how Swedish address forms underwent a radical change in address conventions in a matter of a few decades. Before the late 1960s, Swedish address was characterized by an intricate system of using $\mathrm{V}$ address, titles and last names to address those other than family and close friends, which was then replaced by a nearly universal use of the informal $\mathrm{T}$ form $d u$. This change - commonly referred to as the $d u$-reform - to a no-nonsense, egalitarian $d u$ represented a shift 'from below' (i.e., led and spread by the people) rather than being a prescribed reform 'from above', imposed by the government. Fremer's study is based on commercials in the archival film collections of the Swedish Film Institute. These data provide a unique opportunity to analyse address forms in context, as they were used while the reform was taking place. By focusing on the first examples of $d u$ found outside of the intimate contexts of family and close friends, the chapter argues that certain contexts, like rhymes and songs, or the use of inner dialogue, facilitate the use of $d u$ where formal address for addressing the viewers otherwise would be expected. The general tendency in Sweden towards greater informality in public contexts as well as the radical political climate around 1970 changed not only the style of address, but also language in a more general sense, as well as the looks and behaviour of the protagonists in the film commercials studied. The chapter illustrates 
how changes in address practices went hand in hand with a general tendency in society towards informality in terms of appearance, manners and language.

In Chapter 4, Catrin Norrby, Camilla Wide, Jenny Nilsson and Jan Lindström present a study of address practice and interpersonal relationships in Finland-Swedish and Sweden-Swedish service encounters. The chapter draws on new data collected within the bi-national comparative research programme Interaction and Variation in Pluricentric Languages: Communicative Patterns in Sweden Swedish and Finland Swedish, which compares pragmatic and interactional patterns in the domains of service, higher education and healthcare. The chapter explores how staff and customers address each other in some 300 service encounters collected at theatre box offices and similar settings in Finland and Sweden. Address practices in the two datasets are compared both from a quantitative and qualitative perspective. The data confirm some expected tendencies; for example, that $\mathrm{T}$ address is clearly the default pattern in Swedish and that $\mathrm{V}$ address is primarily used (to some extent) in Finland. A less expected result of the study is that, among customers, the biggest difference in use of $\mathrm{T}$ address exists between younger and older customers in Sweden, not between customers in the two countries. Among staff, the greatest variation in address practices can clearly be found among younger Finland-Swedish staff members, who use all the address patterns found in the data. The qualitative analysis also shows that $\mathrm{T}$ and $\mathrm{V}$ address can be used in the same service encounter, which further illustrates the dynamic character of address patterns in Swedish, and in Finland Swedish in particular.

Johanna Isosävi and Hanna Lappalainen's Chapter 5 also examines service encounters, from a global perspective. The authors focus on Starbucks, an American multinational corporation that seeks to transfer informal American styles of interaction to its branches in other countries. They compare customers' attitudes towards the use of first names in Starbucks cafés in Finland and France by examining Internet postings, observing authentic service situations, and interviewing waiters and clients. The comparison of Finland and France opens up several interesting perspectives. In Finland, the coffee chain had just opened its first cafés when Isosävi and Lappalainen collected their data (2012-2013), whereas the first cafés in France opened in 2004 - over ten years later, Starbucks is well established, with 39 cafés in Paris alone. T forms are generally favoured in Finnish address culture, but the use of first 
names is often avoided, even in multi-party conversations. In France, $\mathrm{V}$ address, which is the default choice in institutional conversations, can be combined with first names in long-term service encounters, even though first names are typically not used. The authors' examination of the social meanings and language ideologies related to the use of first names in Starbucks cafés reveals the complexities of transferring external, global norms of interaction into new local settings.

Chapter 6, by Maicol Formentelli and John Hajek, focuses on the social rituals of positioning self and others in the context of higher education. Recent studies have confirmed the importance of address in marking power and distance in higher education across languages and national varieties of the same language. However, up-to-date research is still limited for languages like Italian, where there is great individual, regional and stylistic variation both in the repertoire and in the use of pronominal address forms. This chapter offers the first detailed description of address practices in Italian academic interactions, based primarily on questionnaire responses from students at two small- and medium-sized universities in Northern Italy. The results show that the use of reciprocal V form Lei between lecturers and students is the main strategy to convey respect and social distance, along with lexical $\mathrm{V}$ forms (honorifics, titles, last names). At the same time, and somewhat unexpectedly, non-reciprocal address with an increasing use of $\mathrm{T}$ forms from lecturers to students also seems to be gaining ground. The authors argue that their findings confirm the recent claims of a gradual expansion of informality in Italian society. However, they also demonstrate a resistance to completely abandoning formality in education, where the explicit acknowledgement of the teacher's authority through the use of $\mathrm{V}$ forms by students is still perceived as the natural reflection of different roles and age.

The volume concludes with reflections by Jane Warren that situate the empirical chapters in the broader context of address research. It outlines how each study contributes to the theme of the volume: address as a form of social action through which social and interpersonal relationships are encoded and negotiated in and across cultures and languages.

\section{References}

Agha, A. (2007) Language and Social Relations Cambridge: Cambridge University Press. 
Braun, F. (1988) Terms of Address: Problems of Patterns and Usage in Various Languages and Cultures Berlin: Mouton de Gruyter.

Brown, P. and Levinson, S. (1987) Politeness. Some Universals in Language Usage Cambridge: Cambridge University Press.

Brown, R. and Gilman, A. (1960) 'The pronouns of power and solidarity' in T. A. Sebeok (ed.) Style in Language Cambridge, MA: MIT Press, pp. 253-76.

Clark, H. H. (1996) Using Language Cambridge: Cambridge University Press.

Clyne, M. (1992) Pluricentric Languages. Differing Norms in Different Nations Berlin: Mouton de Gruyter.

Clyne, M., Norrby, C. and Warren, J. (2009) Language and Human Relations. Styles of Address in Contemporary Language Cambridge: Cambridge University Press.

Ervin-Tripp, S. (1986) 'On sociolinguistic rules: alternation and co-occurrence. Directions in sociolinguistics' in J. Gumperz and D. Hymes (eds) The Ethnography of Communication Oxford: Blackwell, pp. 213-50.

Fredsted, E. (2005) 'Politeness in Denmark. Getting to the point' in L. Hickey and M. Stewart (eds) Politeness in Europe Clevedon: Multilingual Matters, pp. 159-73.

Gardner-Chloros, P. (2007) 'Tu/vous choices: An "act of identity"?' in M. Jones and W. Ayres-Bennett (eds) The French Language and Questions of Identity Oxford: Legenda, pp. 106-16.

Hickey, L. and Stewart, M. (eds) (2005) Politeness in Europe Clevedon: Multilingual Matters.

Leech, G. (1983) Principles of Pragmatics London: Longman.

Mühlhäusler, P. and Harré, R. (1990) 'You: The grammatical expression of social relations' in P. Mühlhäusler and R. Harré (eds) Pronouns and People: The Linguistic Construction of Social and Personal Identity Oxford: Blackwell, pp.131-67.

Norrby, C. and Warren, J. (2012) 'Address practices and social relationships in Europe', Language and Linguistics Compass, 6.4, 225-35. Norrby, C., Wide, C., Lindström, J. and Nilsson, J. (2015) 'Interpersonal relationships in medical consultations. Comparing Sweden Swedish and Finland Swedish address practices', Journal of Pragmatics, 84, 121-38.

Paulston, C. Bratt (1976) 'Pronouns of address in Swedish: social class semantics and a changing system', Language in Society, 5, 359-86. 
Svennevig, J. (1999) Getting Acquainted in Conversation: A Study of Initial Interactions Amsterdam: Benjamins.

Trap-Jensen, L. (1995) 'Danske tiltalepronominer: en empirisk undersøgelse af normer og brug', SPRÅU, 2-1995, 89-101.

Watts, R. (2003) Politeness Cambridge: Cambridge University Press. Yli-Vakkuri, V. (2005) 'Politeness in Finland: Evasion at all cost' in

L. Hickey and M. Stewart (eds) Politeness in Europe Clevedon: Multilingual Matters, pp. 189-202.

(c) (i) Except where otherwise noted, this work is licensed under a a copy of this license, visit https://creativecommons.org/version4 